\title{
TO WHAT EXTENT DOES THE CURRENT EU REGULATORY FRAMEWORK FOR CIVILIAN DRONES ADDRESS PRIVACY ISSUES?
}

\author{
Natia Jiniuzashvili \\ Guest Lecturer, \\ Georgian National University SEU
}

"Drones can be a highly effective way of dealing with high-priority targets, but they should not become the drug of choice for an administration that is afraid to use successful, legal and safe tactics of the past". ${ }^{1}$

\begin{abstract}
Drone operation for civil purposes is a path-breaking innovation for all sectors of society. Drones, which were initially used for military purposes only, are currently widely applied for different civil purposes, such as recreational and commercial use, disaster relief, agriculture, construction management and other purposes. The drone industry is expected to employ more than 100,000 people and have an economic impact for more than $€ 10$ billion annually by 2025 . $^{2}$ To achieve their full potential, it is vitally important to assess the potential risks drones might pose considering their characteristics and how this risk could be eliminated. It is also globally acknowledged that drones need to be integrated into non-segregated airspace, without compromising the achieved standards of civil aviation for manned aircraft in any way.

There are very important aspects linked to drone operation that are equally relevant to individuals both on the ground and in the air as well as to states and users of the airspace of interest for both manned and unmanned aircraft operation, among them is privacy. There are no direct instruments addressing privacy concerns related to drone operation. Therefore, existing treaties and regulations should be examined to determine whether these privacy issues are covered by national, regional and global regulatory frameworks of the EU. As stressed in the Riga Declaration: "Public acceptance is key to the growth of drone services". Therefore, addressing privacy issues sufficiently is a permanent force affecting the growth of the drone industry.
\end{abstract}

Key words: Drones, Civil Liability, Unmanned Aerial Systems, Privacy, Personal data protection.

\section{Introduction}

"Drones offer new services and applications going beyond traditional aviation and offer the promise to perform existing services in a more affordable and environmentally friendly way. They are a truly transformational technology." 3 The EU showed interest in drones and started a global discussion about them since the adoption of the Riga Declaration. ${ }^{4}$ It was followed by several studies, soft law instruments and lately by two implementing and delegating regulations. The EU and its Member States are engaged in different projects through various platforms such as Concept of Operations for European UTM System (CORUS) and Proving Operations of Drones with Initial UTM (PODIUM), ${ }^{6}$ dedicated to the development of the drone industry. Modern drones have been used extensively for civil purposes such as agriculture, tourism, disaster relief, waste management and construction planning. It is anticipated that the drone industry will employ more

\footnotetext{
${ }^{1}$ J. A. Rodriguez, Jr. https://www.quoteload.com/quotes/authors/jose-a-rodriguez-jr/39352-drones-can-be-a-highly-effective-way-ofdealing-with-high-priority-targets-but-they-should-not-become-the-drug-of-choice-for-an-administration-that-is, [1. s. 08.10.2021].

${ }^{2} \mathrm{https}: / /$ ec.europa.eu/growth/sectors/aeronautics/rpas_en, [L. s. 08.10.2021].

${ }^{3}$ See 2.

${ }^{4}$ Riga Declaration on Remotely Piloted Aircraft (drones) "Framing the Future of Aviation”, Riga, 6 March, 2015.

${ }^{5}$ A set of easy-to-use rules for low-level airspace operations, https://www.sesarju.eu/projects/corus, [1. s. 11.10.2021].

${ }^{6}$ Putting U-space services to the test in operational scenarios, https://www.sesarju.eu/projects/podium, [1. s. 11.10.2021].
} 
than 100,000 persons and have an economic impact of more than $€ 10$ billion annually by $2025 .^{7}$ Drones must be incorporated into non-segregated aviation in order to realize their full potential. Therefore, all stakeholders including private entities, international organizations such as EUROCONTROL and supranational organizations such as the EU are all cooperating to achieve this integration.

Along with the possibility of drones to be integrated into non-segregated airspace, they need to gain public acceptance, which is key to the growth of the drone industry. The general public is concerned about privacy, issues meaning that drones, considering the payload they carry and the capabilities they are equipped with, should not infringe on the privacy rights of the public; should not process information that will violate data protection rights;

This article aims to address this concern in the following manner. The first chapter tries to identify whether drones should be considered as aircraft, based on what should be considered as an aircraft. It is an important aspect to determine the aviation-related regulations applicable to them. Also, this chapter will briefly overview the history of its transition from military to non-military applications. There are different terms used to refer to drones, such as unmanned aircraft, autonomous aircraft, remotely piloted aircraft, etc.

The second chapter will explore the concept of the right to privacy: whether it is an absolute right or there are some limitations and under what circumstances is derogation permitted. Drones themselves do not pose a risk to the right to privacy, but a payload with the capacity to process data does. Accordingly, this chapter will enunciate where the legal boundary between collecting information for determined purposes and violation of privacy and personal data protection is to be found. Also, possible forms of breach of the above-mentioned rights will be elaborated, such as functional creep, voyeurism, infringement of bodily privacy and geolocalization. The regulatory framework for drones neither before the EC Regulation 2019/947 not afterwards does not directly address privacy issues; hence, the privacy and personal data rights found their legal safeguard under other legal instruments, such as the Convention for the Protection of Human Rights and Fundamental Freedoms of 1950, the Charter of Fundamental Rights of the EU, the Directive 95/46/EC on the protection of individuals with regard to the processing of personal data and on the free movement of such data 9 and the General Data Protection Regulation. This chapter will assess whether the new Regulation has changed the existing situation, to what extent are privacy and personal data protection rights addressed in it and if this protection corresponds to the requirements set by legislative instruments particularly addressing privacy and personal data protection issues.

To answer the above-mentioned questions, qualitative research will be conducted. The existing literature does not sufficiently address these realms; therefore, for the research, along with the existing literature, international conventions, case law of the European Court of Human Rights (ECHR), EU Regulations, Directives, soft law instruments, different internet sources and other sources will be used to provide an answer to the following question: to what extend does the current EU regulatory framework for civilian drones address privacy issues?

\section{History, definitions and taxonomy}

\subsection{Aircraft, vehicles or something else?}

The Paris Convention 1919 Relating to the Regulation of Aerial Navigation was the first attempt to regulate civil aviation at the international level. ${ }^{8}$ It did not include any specific articles concerning drones. However, the Protocol of 15 June 1929 incorporated a legal provision regarding pilotless aircraft in Article 15(2) stating the following: "No aircraft of a contracting State capable of being flown without a pilot shall, except by special authorization, fly without a pilot over the territory of another contracting State". 9 The Paris Convention 1919

\footnotetext{
7 See 4.

${ }^{8}$ B. I. Scott, A. Trimarchi, "Fundamentals of International Aviation Law and Policy", "Routledge", at 25, 2020.

${ }^{9}$ Article 8, Convention on International Civil Aviation, signed on 7 December 1944, in Chicago.
} 
was replaced by the Chicago Convention on International Civil Aviation 1944 (hereinafter Chicago Convention). ${ }^{10}$

The US did not adhere to the Paris Convention as it considered the Convention to not sufficiently address the concept of freedom of commerce and transport. By the time WWII ended, commercial air transport had almost collapsed due to hostilities and the US initiated the establishment of a new regulatory framework. ${ }^{11}$ The Chicago Convention aimed to develop international civil aviation in a safe and orderly manner, such that international air transport services would be established based on equality and opportunity and operated soundly and economically. ${ }^{12}$

ICAO has recognized the importance of drones and their future perspectives and to achieve the goals mentioned above, on 19 April 2007, the Unmanned Aircraft System Study Group was established. Subsequently, on 6 May 2014, the Remotely Piloted Aircraft System Panel was established. In 2011, the Unmanned Aircraft System Circular 328 was published, ${ }^{13}$ and it was followed by the Manual on Remotely Piloted Aircraft Systems Doc 10019 and the process to develop a more sophisticated regulatory framework is ongoing. The EU has also kept up with global developments by regulating drones with an MTOM equal to or greater than $150 \mathrm{~kg}$ by the EASA Basic Regulation 216/2008 ${ }^{14}$ and currently by adopting Implementing Regulation 2019/947 ${ }^{15}$ and Delegated Regulation 2019/945. ${ }^{16}$

To understand whether or not the regulatory framework developed for civil aircraft operation applies to drones, firstly the legal status of the drones should be determined. Article 8 of the Chicago Convention incorporated the provision concerning pilotless aircraft adopted in Article 15(2) of the Paris Convention 1919 as amended by the Protocol of 15 June 1929. ${ }^{17}$ However, neither Article 15(2) of the Paris Convention nor Article 8 of the Chicago Convention includes a precise definition of what is considered as a pilotless aircraft. Annex 7 to the Chicago Convention includes the definition of an aircraft, which states that "any machine that derives support in the atmosphere from the reactions of the air other than the reaction of the air against the earth's surface". ${ }^{18}$ Article 8 does not specify any characteristics of a pilotless aircraft; it, however, does states that the following: "No aircraft capable of being flown without a pilot shall be flown without a pilot over the territory of a contracting State without special authorization by the State and in accordance with the terms of such authorization". ${ }^{19}$ Accordingly, a "pilotless aircraft" can be interpreted simply as without pilot, thus including both unmanned aircraft flying autonomously and those operated remotely. This understanding was later confirmed by the Global Air Traffic Management Operational Concept. ${ }^{20}$ Subsequently, the sixth amendment to Annex 7 included the definition of RPA - an unmanned aircraft, which is piloted from a remotely piloted station. ${ }^{21}$ The ICAO approach once again confirms that both autonomous and remotely piloted aircraft shall be considered as pilotless aircraft for the purposes of Article 8 of the Chicago Convention, and therefore, relevant regulations shall be applicable.

\footnotetext{
${ }^{10}$ See 9 .

${ }^{11}$ L. Weber, "The Chicago Convention", in P.S. Dempsey, R.S. Jakhu (ed.), "Routledge Handbook of Public Aviation Law", at 9 , 2017.

${ }^{12}$ See 9 , Preamble.

${ }^{13}$ ICAO, Unmanned Aircraft Systems (UAS), Cir 328 AN/190, 2011.

${ }^{14}$ Regulation (EC) No. 216/2008 of the European Parliament and of the Council of 20 February 2008 on common rules in the field of civil aviation and establishing a European Aviation Safety Agency, and repealing Council Directive 91/670/EEC, Regulation (EC) No. 1592/2002 and Directive 2004/36/EC.

${ }^{15}$ Commission Implementing Regulation (EU) 2019/947 of 24 May 2019 on the rules and procedures for the operation of unmanned aircraft.

${ }^{16}$ Commission Delegated Regulation (EU) 2019/945 of 12 March 2019 on unmanned aircraft systems and on third-country operators of unmanned aircraft systems.

${ }^{17}$ The Protocol Concerning Amendments to Articles 3, 5, 7, 15, 34, 37, 41 and 42 and the final provisions of the Convention Relating to the Regulation of Aerial Navigation 13 October 1919, cited as the Protocol of June 151929 amending the Paris Convention 1919, entered into force on 17 May 1933.

${ }^{18}$ Annex 7 to the Convention on International Civil Aviation - Aircraft Nationality and Registration Marks, at Definitions.

${ }^{19}$ See 2 , Article 8 .

${ }^{20}$ ICAO, Global Air Traffic Management Operational Concept, Doc 9854 AN/458, at 82, 2005.

${ }^{21}$ A set of easy-to-use rules for low-level airspace operations, https://www.sesarju.eu/projects/corus [1. s. 08.10.2021].
} 
Taking into account the fact that drones were in existence and used during WWI and WWII, ${ }^{22}$ as per Article 31(1) of the Vienna Convention 1969, it can be assumed that parties to the Chicago Convention intended to consider them, and that interpreting Article 8 in "good faith" and "in the light of objects and purpose" 23 shall indeed include both autonomous and remotely piloted aircraft. Accordingly, all regulations concerning civil aircraft including safety and security requirements apply to drones, considering their particularities.

\subsection{Short historical overview of non-military drones}

One of the earliest known self-propelled unmanned aircraft systems was Archytas' Pigeon circa 425 BC, which was created to understand the mechanism of birds' flight. ${ }^{24}$ Chinese culture also had an ancestor of the drone, the "Chinese top" - a stick with feathers at the end. Egyptian Saqqara Birds dating back to 200 BC was another attempt to understand the rules of aerodynamics. ${ }^{25}$

Even though more advanced ancestors of current drones have almost a century-long history, public awareness of drones has only grown in recent years. Previously used for military purposes, drones' civil use has become more and more common. In 1818, an airborne balloon was designed by a French 3 solider, which would hover over enemies and launch rockets down on top of them. ${ }^{26}$ In 1894, Austrians used unmanned balloons with bombs to invade Venice. ${ }^{27}$ In 1898 , the US used unmanned kites equipped with cameras for aerial surveillance during the Spanish-American War. In the 1898 patent "Methods of and Apparatus for Controlling Mechanism of Moving Vessels or Vehicles", Tesla was the first who predicted the use of military unmanned vehicles. ${ }^{28}$ The first unmanned aircraft was used during WWI, when in 1917 the Hewitt-Sperry Automatic Airplane performed its first flight. It was a remarkable achievement, as it represented a technological progression by incorporating a gyrostabilizer, thus preventing the aircraft from rolling. It was followed by the Ketting Bug in 1918 - a predecessor of modern cruise missiles, ${ }^{29}$ then Larynx in 1927, Fairy Queen in 1931 and DH 82B, nicknamed as "Queen bee". The latter is considered to have laid the foundation for the term drone, which is the name for a male bee that chases the queen bee, as DH82B was intended to be chased by fighter aircraft. ${ }^{30}$

The first massively produced drone was OQ-2, which was used during WWII along with OQ-3. ${ }^{31}$ The Vergeltungswaffe 1 (V1) was a German UAS operated during WWII, which was directed towards the target aimed to crash after a set time. ${ }^{32}$ The MQM-57 Falconer was the first drone used for aerial inspection. ${ }^{33}$ Ryan Firebee drones were used during the Vietnam War and Iraq invasion. MQ-1 was used in Afghanistan, Pakistan, Bosnia, Syria and Somalia. The heavier and more powerful version MQ-9 was used in Iraq in 2007, and it is still used in Afghanistan. ${ }^{34}$

\footnotetext{
${ }^{22}$ The Secret History of World War II-Era Drones, https://www.wired.com/2015/12/the-secret-history-of-world-war-ii-era-drones/, [1.s. 08.10.2021].

${ }^{23}$ Article 31(1), Vienna Convention on the Law of Treaties Done at Vienna on 23 May 1969.

${ }^{24}$ K. Dalamagkidis et al., "On Integrating Unmanned Aircraft Systems into the National Airspace Systems", at 12, 2012.

${ }^{25}$ D. Hodgkinson, R. Johnston, Aviation Law and Drones - "Unmanned Aircraft and the Future of Aviation", "Routledge", at 4, 2018.

${ }^{26}$ Gregory K. James, Unmanned Aerial Vehicles and Special Operations: Future Directions (Postgraduate Thesis, Monterey California Naval Postgraduate School) at 5, 2000.

${ }^{27}$ The First Air Raid Happened When Austria Dropped Bombs on Venice from Pilotless Hot-Air Balloons (1849), http://www.findingdulcinea.com/news/on-this-day/July-August-08/On-this-Day--Austria-Rains-Balloon-Bombs-on-Venice.html, [1. s. 08.10.2021].

${ }^{28}$ The History of Drone Warfare, https://www.thoughtco.com/history-of-drones-4108018, [1. s. 08.10.2021].

${ }^{29}$ See 8 , at 6.

${ }^{30}$ A. Masutti, F. Tomasello, International regulation of non-military drones, Edward Publishing Limited, at 4, 2018.

${ }^{31}$ B. A Whitmore, Evolution of Unmanned Aerial Warfare: A Historical Look at remote Airpower - A Case Study Innovation, A thesis presented to the Faculty of the U.S. Army Command and General Staff College in partial fulfillment of the requirements for the degree, at 16,2016

32 B. I. Scott, Overview in B. I. Scott (ed.), The Law of Unmanned Aircraft Systems: An Introduction to the Current and Future Regulation under National, Regional and International Law, Wolters Kluwer, at 4, 2016.

${ }^{33}$ H. Gonzalez-Jorge, J. Martinez-Sanchez, M. Bueno, P. Arias, Unmanned Aerial Systems for Civil Applications: A Review, MDPI, at $1,2017$.

${ }^{34}$ See 8 , at 8
} 
Because drones were mainly used for military purposes throughout history, they were associated mainly with military operations. ${ }^{35}$ However, this viewpoint has changed and the trend of their civil application grew in the 1990s when NASA developed the solar-powered Helios and Pathfinder; ${ }^{36}$ in the same period, Japan widely used drones for spraying crops with fertilizers and pesticides. ${ }^{37}$ Drones were used to fly into the eye of Hurricane Noel..$^{38}$ The introduction of the Phantom by China-based Da-Jiang Innovations, considered to be the precursor to modern consumer drones, included a high-quality GoPro 4 Camera. ${ }^{39}$ In 2013, BBC used a hexacopter to conduct its first drone-assisted reporting. ${ }^{40}$ The popularity and application of drones are rapidly growing and seven million drones are expected to be sold in the US alone by $2020 .{ }^{41}$

\subsection{Terminology to refer to drones and their differences}

There are various terms used to refer to drones, but each has its particularities and the demarcation is very important to understand the drone's nature and operational characteristics and to apply relevant regulations. Drones are widely used in media and are well-known among the general public. This is also the reason why the term "drone" will be used throughout this thesis, excluding the parts where it will be necessary to refer to certain types of drones or regulations, which apply particular terms. The term drone was originally used in military operations; however, this has lately changed, although the term is not used in legislation.

Widely used are terms include Unmanned Aerial Vehicle (UAV) and Unmanned Aerial System (UAS). Regulation 2019/947 and Regulation 2019/945 use the term UAS, and so does the ICAO in its recent documents.

Another term used is Remotely Piloted Aircraft System (RPAS), which considers unmanned aerial systems that are remotely controlled by a pilot. This refers to the entire system, which may include a remotely piloted aircraft, the operator, communication and data links, satellites, remote pilot stations, additional staff, support systems and any other parts necessary for operation. This term underlines the existence of the pilot, which is not always mandatory, as some drones are programmed to operate autonomously. Regulation 2019/947 defined UAS as "an unmanned aircraft and the equipment to control it remotely". ${ }^{42}$ Depending on the nature of the drone, terms such as unmanned aircraft and autonomous aircraft are also used, which tend to refer to autonomously operated drones without human interference. They do not require pilot intervention or act in a predetermined way; instead they act in a pragmatic manner by using the environment to make decisions. ${ }^{43}$ They have been referred to as unmanned drones as well. ${ }^{44}$

\footnotetext{
${ }^{35}$ B. Custers, Drones Here, There and Everywhere: Introduction and Overview in B. Custers (ed.), The Future of Drone Use: Opportunities and Threats from Ethical and Legal Perspectives, at 11, 2016.

${ }^{36}$ NASA Armstrong Fact Sheet: Helios Prototype https://www.nasa.gov/centers/armstrong/news/FactSheets/FS-068-DFRC.html, [1. s. 08.10.2021].

37 Japanese firm to use drone to force overtime staff to go home, https://www.thenational.ae/business/japan-uavs-take-the-backbreaking-labour-out-of-farming 1.221693, [1. s. 08.10.2021].

38 NASA and NOAA Fly Unmanned Aircraft into Hurricane Noel, https://www.nasa.gov/centers/wallops/news/story105.html, [1. s. 08.10.2021].

39 First Click: I, for one, welcome our Chinese drone overlords https://www.theverge.com/2016/1/20/10796844/Drones-rise-chineseinnovation, [1. s. 08.10.2021].

${ }^{40}$ BBC: A bird's eye view of breaking news, https://www.cbinsights.com/research/report/corporations-drone-technology/\#bbc, [1. s. 08.10.2021].

${ }^{41}$ Euro vision: unravelling the new pan-European drone regulations, https://www.airport-technology.com/features/new-eu-dronerules/, [1. s. 08.10.2021].

${ }^{42}$ See 13.

${ }^{43}$ ICAO, Manual on Remotely Piloted Aircraft Systems (RPAS), Doc 10019 AN/507, at Definitions.

${ }^{44}$ See 8 , Article 2 (1).
} 


\section{Drone operation, privacy risks and data protection}

\subsection{Concept of privacy and its limitations}

Concerns have grown in relation to drones and the payload they carry. Payload often considers filming, taking pictures, collecting and processing of personal data, processing biometric data, GPS systems processing the location of persons, tracking them, etc. Therefore, drone operation might pose serious risks to the right to privacy. ${ }^{45}$

Samuel D. Warren and Louis D. Brandeis developed the first concept of privacy and defined it as the "right to be left alone". ${ }^{46}$ Already, more than a century ago, it was recognized that emerging technologies would pose a threat to privacy. The right to be left alone was later recognized by Article 12 of the Universal Declaration of Human Rights of 10 December 1948 stating that "no one shall be subjected to arbitrary interference with his privacy, family, home or correspondence, nor attacks upon his honour and reputation. Everyone has the right to the protection of the law against such interference or attacks". ${ }^{47}$

Later, Article 8 of the European Convention on Human Rights (ECHR) also recognized the right to respect for private life. The right to respect for private life is also recognized under Article 7 of the Charter of Fundamental Rights of the EU. However, the right to respect for private life is not an absolute right, as derogations are permitted under limited circumstances, including in the interest of national security, public safety or protection of health. ${ }^{48}$ The Convention for the protection of individuals with regard to automatic processing of personal data of 28 January 1981 (Privacy Convention), "recognizing that it is necessary to reconcile the fundamental values of the respect for privacy and the free flow of information between peoples", under Article 9 allows derogations for "(a) protecting State security, public safety, the monetary interests of the State or the suppression of criminal offenses; (b) protecting the data subject or the rights and freedoms of others". ${ }^{49}$

Article 15 of the Constitution of Georgia protects rights to personal and family privacy, personal space and privacy of communication, section two of this article defines those situations when the infringement of this right is legitimate: "These rights may be restricted only in accordance with law for ensuring national security or public safety, or for protecting the rights of others, insofar as is necessary in a democratic society, based on a court decision or without a court decision in cases of urgent necessity provided for by law. In cases of urgent necessity, a court shall be notified of the restriction of the right no later than 24 hours after the restriction, and the court shall approve the lawfulness of the restriction no later than 24 hours after the submi ssion of the notification." Georgia is also party to the most of the above-mentioned international instruments which are construed to protect right to privacy.

Regardless of the resistance from the ECHR to define privacy in order to avoid restriction of its applicability to possible privacy right violations, there are still four dimensions of privacy identified in literature - bodily privacy, privacy of personal behaviour including reasonable expectation of privacy right even in public places, privacy of personal communications and privacy of data. ${ }^{50}$

In the case of von Hannover v. Germany, the European Court of Human Rights reiterated that the right to respect for private life extends to protection of one's personal identity, including their photo, and that a person therefore has the right to control the use of their image. ${ }^{51}$ The court emphasized that a person 9

\footnotetext{
${ }^{45}$ DG for Internal Policies - Policy Department Citizen's Rights and Constitutional Affairs, Privacy and Data Protection implications of the civil use of drones, at 23, 2015.

${ }^{46}$ S. D. Warren and L. D. Brandeis, 'The right to privacy', Harvard Law Review, 4 (5), 193 at 220, 1890.

${ }^{47}$ Article 12, The Universal Declaration of Human Rights, signed on 10 December 1948, Paris, General Assembly Resolution 217A.

48 Article 8(2), Convention for the Protection of Human Rights and Fundamental Freedoms, signed in Rome on 4 November 1950.

${ }^{49}$ Article 9, Convention for the Protection of Individuals with regard to Automatic Processing of Personal Data, signed in Strasbourg on 28 January 1981.

${ }^{50}$ See 20 , at 216.

51 Von Hannover v. Germany, 40660/08 [2012] ECHR, para 95-96 (7 Feb. 2012).
} 
may rely on a "legitimate expectation" of protection of and respect for private life, subject to circumstances such as their celebrity and the location in which the photograph was captured. ${ }^{52}$

The European Court of Human Rights in Uzun v. Germany also stressed that "GPS surveillance is by its very nature to be distinguished from other methods of visual or acoustical surveillance which are, as a rule, more susceptible of interfering with a person's right to respect for private life, because they disclose more information on a person's conduct, opinions or feelings". ${ }^{53}$

The EU Commission lists possible ways of privacy infringement, such as the chilling effect (individuals censoring their behaviour), freedom of expression, participation in activities out of fear, ${ }^{54}$ dehumanization of the surveilled by collecting sensitive data about the person without the right to participation of the person surveilled ${ }^{55}$ voyeurism meaning spying on a person while he/she is engaged in a private activity ${ }^{56}$ function creep (use of vehicle or data acquired for purposes other than those intended) ${ }^{57}$ bodily privacy infringement, and violation of privacy of location, space or association. ${ }^{58}$

Considering the capabilities of drones and their ongoing technological advancement, the wide scope of the right to privacy including all the case law developments in related realms, as well as the possible limitations of the privacy right.

\subsection{To what extent does the EU regulatory framework for drones protect the right to privacy?}

Several EU regulatory instruments concern privacy. The fundamental and bases for subsequent regulations are Article 8 of the Convention for the Protection of Human Rights and Fundamental Freedoms and Article 7 of the Charter on Fundamental Right of the EU. They are generic by nature and do not give any rules on how to ensure a sufficient level of protection of the right to privacy; however, they do indicate that this right is not absolute and there might be cases where infringement is legal. ${ }^{59}$

There is no concrete instrument addressing privacy issues in terms of drone operation; however, Regulation 2019/947 and Regulation 2019/945 address privacy risks to some extent. Regulation 2019/947 recital 14 states that drone operator, whose activities might pose risk to privacy, personal data protection, security and the environment, should register his/her drone. Recital 18 also considers the possibility for Member States to additionally regulate the operation of drones to protect privacy and personal data. The Regulation also considers the obligation of UAS operators to be adequately informed about applicable EU and national rules related to safety, privacy, data protection and other relevant issues. ${ }^{60}$ Regulation 2019/945 makes reference to Article 55 of Regulation 2018/1139, ${ }^{61}$ with the latter referring to its Annex 9, which sets requirements for

\footnotetext{
52 See 52 , at para 51.

${ }^{53}$ Uzun v. Germany, 35623/05 [2010] ECHR, para 52 (2 Dec. 2010).

${ }^{54}$ Two sides of the same coin - the right to privacy and freedom of expression, https://privacyinternational.org/blog/1111/two-sidessame-coin-right-privacy-and-freedom-expression, [1. s. 11.10.2021].

${ }^{55}$ See 20 , at 211.

${ }^{56}$ A. Mckenna, The Public Acceptance Challenge and Its Implications for the Developing Civil Drone Industry, in (ed.) B. Custers, The Future of Drone Use, Opportunities and Threats from Ethical and Legal Perspective, at 366, 2016.

${ }^{57}$ Opinion of the European Data Protection Supervisor on the amended proposal for a Regulation of the European Parliament and of the Council on the establishment of 'EURODAC' for the comparison of fingerprints for the effective application of Regulation, at 7.

${ }^{58}$ European Commission, Study on privacy, data protection and ethical risks in civil Remotely Piloted Aircraft Systems operations Summary for Industry, 7, 2014.

59 From Retailers to Insurance Providers, Here Are 21 Corps Using Drone Tech Today, https://www.cbinsights.com/research/report/corporations-drone-technology/\#bbc, [1. s. 08.10.2021].

${ }^{60}$ See 8 , Article 2(17).

${ }^{61}$ Regulation (EU) 2018/1139 of the European Parliament and of the Council of 4 July 2018 on common rules in the field of civil aviation and establishing a European Union Aviation Safety Agency, and amending Regulations (EC) No. 2111/2005, (EC) No. 1008/2008, (EU) No. 996/2010, (EU) No. 376/2014 and Directives 2014/30/EU and 2014/53/EU of the European Parliament and of the Council, and repealing Regulations (EC) No. 552/2004 and (EC) No. 216/2008 of the European Parliament and of the Council and Council Regulation (EEC) No. 3922/91, Article 55.
} 
design, production, maintenance and operation of drones and stipulates almost the same narrative as Regulation 2019/947, that is, the operator and remote pilot should be aware of applicable union and national rules related to a number of issues, including privacy and data protection. This adds to the responsibility of the manufacturer to include features and functionalities while designing drones to take into account the principles of privacy and protection of personal data. ${ }^{62}$ All references to privacy and data protection indicate the obligation of registration and ensuring compliance of drone operation to applicable EU and national rules regulating those issues; therefore, to identify how drones should be operated to avoid infringement of the right to privacy and data protection, relevant regulations should be referred to.

The Convention for the Protection of Individuals concerning Automatic Processing of Personal Data also recognizes the importance of the right to privacy and especially regulates automatic processing of personal data. The Convention sets requirements for automatically processed data that this data should be obtained and processed fairly and lawfully, stored for specified and legitimate purposes and not used in a way incompatible with those purposes, prohibiting automatic processing of data revealing racial origin, political opinion or religious or other beliefs, as well as concerning health and sexual life. ${ }^{63}$ This requirement can be applied to drone operation, restricting the drone's ability to automatically process data that can reveal the abovementioned information about a person.

According to the Common Aviation Area agreement between European union and its Member States and Georgia undertakes to take appropriate measures to bring its national legislation closer to that of the European Union. ${ }^{64}$ For this reason Order \#156 of the Director of Civil Aviation of Georgia of September 25, 2020 has been adopted to implement Regulation 945/2019 and Regulation 947/2019. As a result of the operation of drones against potential violations of the right to privacy, we have exactly the same situation as in the EU and we should be guided by the human rights instruments that provide for the protection of the right to privacy.

Directive 2002/58 also refers to privacy and its protection in the electronic communication sector. The Directive recognizes technological advancement and its application in public communications networks. It sets requirements for the processing of electronic communications including confidentiality, technical standardization and traffic data. ${ }^{65}$ Considering that depending on the payload that drones carry, they might be performing different functions and be used for various purposes, in case they are applied for the electronic communications sector, they would become subject to the requirements of Directive 2002/58.

\section{Conclusion}

Drones offer new capabilities and applications that go beyond conventional aviation and deliver the promise of more efficient and environmentally friendly performance of existing services. They are a revolutionary tool. Drones should be integrated into non-segregated airspace, and at the same time, citizens' concerns related to privacy, safety and security should be adequately dealt with. Drones' potential is seen globally and regionally, including by the EU. The EU sees the drone industry as a creator of jobs and as a tool for economic development. Therefore, it is devoting its resources to research and develop drones and to establish different platforms of cooperation. The EU has adopted new Regulation 2019/947 and Regulation 2019/945 based on the experiences and expertise acquired so far.

Identification of a drone's legal status is vitally important, as it determines the array of rules applicable. Legal demarcation of drones from vehicles such as model aircraft and toy aircraft is also important, as drones, model aircraft and toy aircraft are each regulated separately and by different regulations. While identifying the

\footnotetext{
${ }^{62}$ See 61, Annex IX, Section 1.1.

${ }^{63}$ Article 6, Convention for the Protection of Individuals with Regard to Automatic Processing of Personal Data, signed on January 28, 1981.

${ }^{64}$ Common Aviation Area agreement between European union and its Member States and Georgia, Article 21 (2).

${ }^{65}$ Directive 2002/58/EC of the European Parliament and of the Council of 12 July 2002 concerning the processing of personal data and the protection of privacy in the electronic communications sector.
} 
applicable rules, the characteristics of drones, such as nature of use, size and technical features, should be considered, as the outcome in each case would differ.

It is essential to ensure respect for the fundamental rights of citizens, such as the right to privacy and the protection of personal data. Operation of drones has already raised numerous concerns including privacy and data protection issues considering the payload attached to drones. If the concerns of society are not sufficiently addressed, it will reduce public acceptance of drones and therefore adversely affect the development of the drone industry. Privacy and data protection rights are not absolute, and they can be limited for relevant purposes; however, when they are limited, the measures used should be in compliance with applicable regulations and proportionate to the goal to be achieved. The existing regulatory framework for privacy does not specifically concern drone operation and the threats posed; however, the existing rules can still be applied to drones and respecting them is obligatory according to Regulation 2019/947. Moreover, the application of privacy and data protection regulations should not be too restrictive, as this may hinder the development of the industry; instead a case-by-case approach should be taken to achieve the right balance.

While protecting the right to privacy and personal data protection and regulating drone operation, each case should be assessed individually. The right balance should be achieved between protection of the abovementioned rights and avoiding adverse effects on the development of the drone industry by imprudently restricting it. All the shareholders - civil aviation authorities, manufacturers and drone operators - should cooperate to achieve the sufficient level of protection and growth of the industry cumulatively. 


\section{BIBLIOGRAPHY}

1. Vienna Convention on the Law of Treaties Done at Vienna on 23 May 1969;

2. The Universal Declaration of Human Rights, signed on 10 December 1948, Paris, General Assembly Resolution 217A;

3. Convention for the Protection of Human Rights and Fundamental Freedoms, signed in Rome on 4 November 1950;

4. Convention for the Protection of Individuals with regard to Automatic Processing of Personal Data, signed in Strasbourg on 28 January 1981;

5. Convention on International Civil Aviation, signed on 7 December 1944, in Chicago;

6. Annex 7 to the Convention on International Civil Aviation - Aircraft Nationality and Registration Marks;

7. Regulation (EU) 2018/1139 of the European Parliament and of the Council of 4 July 2018 on common rules in the field of civil aviation and establishing a European Union Aviation Safety Agency, and amending Regulations (EC) No. 2111/2005, (EC) No. 1008/2008, (EU) No. 996/2010, (EU) No. 376/2014 and Directives 2014/30/EU and 2014/53/EU of the European Parliament and of the Council, and repealing Regulations (EC) No. 552/2004 and (EC) No. 216/2008 of the European Parliament and of the Council and Council Regulation (EEC) No. 3922/91;

8. Directive 2002/58/EC of the European Parliament and of the Council of 12 July 2002 concerning the processing of personal data and the protection of privacy in the electronic communications sector;

9. Directive 95/46/EC of the European Parliament and of the Council of 24 October 1995 on the protection of individuals with regard to the processing of personal data and on the free movement of such data;

10. Regulation (EU) 2016/679 of the European Parliament and of the Council of 27 April 2016 on the protection of natural persons with regard to the processing of personal data and on the free movement of such data, and repealing Directive 95/46/EC;

11. Directive 2002/58/EC of the European Parliament and of the Council of 12 July 2002 concerning the processing of personal data and the protection of privacy in the electronic communications sector;

12. Directive 2009/136/EC of the European Parliament and of the Council of 25 November 2009 amending Directive 2002/22/EC on universal service and users' rights relating to electronic communications networks and services, Directive 2002/58/EC concerning the processing of personal data and the protection of privacy in the electronic communications sector and Regulation (EC) No. 2006/2004 on cooperation between national authorities responsible for the enforcement of consumer protection laws;

13. Regulation (EU) 2016/679 of the European Parliament and of the Council of 27 April 2016 on the protection of natural persons with regard to the processing of personal data and on the free movement of such data, and repealing Directive 95/46/ EC;

14. Regulation (EC) No. 216/2008 of the European Parliament and of the Council of 20 February 2008 on common rules in the field of civil aviation and establishing a European Aviation Safety Agency, and repealing Council Directive 91/670/EEC, Regulation (EC) No. 1592/2002 and Directive 2004/36/EC;

15. Commission Delegated Regulation (EU) 2019/945 of 12 March 2019 on unmanned aircraft systems and on thirdcountry operators of unmanned aircraft systems;

16. The Protocol Concerning Amendments to Articles 3, 5, 7, 15, 34, 37, 41 and 42 and the final provisions of the Convention Relating to the Regulation of Aerial Navigation 13 October 1919, cited as the Protocol of June 151929 amending the Paris Convention 1919, entered into force on 17 May 1933;

17. Benjamyn. I. Scott, Andrea. Trimarchi, Fundamentals of International Aviation Law and Policy, Routledge, 2020.; 
18. Ludwig Weber, The Chicago Convention, in Paul Stephen Dempsey, Ram Jakhu (ed.), Routledge Handbook of Public Aviation Law, 2017;

19. Konstantinos Dalamagkidis et al., On Integrating Unmanned Aircraft Systems into the National Airspace Systems, 2012;

20. David Hodgkinson, Rebecca Johnston, Aviation Law and Drones - Unmanned Aircraft and the Future of Aviation, Routledge, 2018;

21. Gregory K. James, Unmanned Aerial Vehicles and Special Operations: Future Directions (Postgraduate Thesis, Monterey California Naval Postgraduate School) 2000;

22. Anna Masutti, Filippo. Tomasello, International regulation of non-military drones, Edward Publishing Limited, at 4, 2018;

23. Bishane A. Whitmore, Evolution of Unmanned Aerial Warfare: A Historical Look at remote Airpower - A Case Study Innovation, A thesis presented to the Faculty of the U.S. Army Command and General Staff College in partial fulfillment of the requirements for the degree, 2016;

24. Benjamyn I. Scott, The Law of Unmanned Aircraft Systems: An Introduction to the Current and Future Regulation under National, Regional and International Law, Wolters Kluwer, 2016;

25. Bart Custers, The Future of Drone Use: Opportunities and Threats from Ethical and Legal Perspectives, 2016;

26. Higinio Gonzalez-Jorge, Joaquin Martinez-Sanchez, Martin Bueno, Pedor Arias, Unmanned Aerial Systems for Civil Applications: A Review, MDPI, 2017;

27. Samuel D. Warren, Louis D. Brandeis, The right to privacy', Harvard Law Review, 4 (5), 1890;

28. ICAO, Unmanned Aircraft Systems (UAS), Cir 328 AN/190, 2011;

29. ICAO, Global Air Traffic Management Operational Concept, Doc 9854 AN/458, at 82, 2005;

30. ICAO, Manual on Remotely Piloted Aircraft Systems (RPAS), Doc 10019 AN/507, at Definitions;

31. DG for Internal Policies - Policy Department Citizen's Rights and Constitutional Affairs, Privacy and Data Protection implications of the civil use of drones, at 23, 2015;

32. Riga Declaration on Remotely Piloted Aircraft (drones) "Framing the Future of Aviation", Riga, 6 March, 2015 ;

33. Opinion of the European Data Protection Supervisor on the amended proposal for a Regulation of the European Parliament and of the Council on the establishment of 'EURODAC' for the comparison of fingerprints for the effective application of Regulation, at 7;

34. European Commission, Study on privacy, data protection and ethical risks in civil Remotely Piloted Aircraft Systems operations - Summary for Industry, 7, 2014;

35. Unmanned aircraft, https://ec.europa.eu/growth/sectors/aeronautics/rpas_en [Last seen: 08.10.2021];

36. A set of easy-to-use rules for low-level airspace operations, https://www.sesarju.eu/projects/corus. [Last seen: 08.10.2021];

37. Putting U-space services to the test in operational scenarios, https://www.sesarju.eu/projects/podium. [Last seen: 08.10.2021];

38. The Secret History of World War II-Era Drones, https:/www.wired.com/2015/12/the-secret-history-of-world-warii-era-drones/. [Last seen: 08.10.2021];

39. The First Air Raid Happened When Austria Dropped Bombs on Venice from Pilotless Hot-Air Balloons (1849), http://www.findingdulcinea.com/news/on-this-day/July-August-08/On-this-Day--Austria-Rains-Balloon-Bombson-Venice.html. [Last seen: 08.10.2021]; 
40. The History of Drone Warfare, https:/www.thoughtco.com/history-of-drones-4108018. [Last seen: 08.10.2021];

41. NASA Armstrong Fact Sheet: Helios Prototype, https://www.nasa.gov/centers/armstrong/news/FactSheets/FS-068DFRC.html. [Last seen: 08.10.2021];

42. Japanese firm to use drone to force overtime staff to go home, https://www.thenational.ae/business/japan-uavs-takethe-back-breaking-labour-out-of-farming 1.221693. [Last seen: 08.10.2021];

43. NASA and NOAA Fly Unmanned Aircraft into Hurricane Noel, https://www.nasa.gov/centers/wallops/news/story105.html. [Last seen: 08.10.2021];

44. First Click: I, for one, welcome our Chinese drone overlords https://www.theverge.com/2016/1/20/10796844/Drones-rise-chinese-innovation. [Last seen: 08.10.2021];

45. From Retailers To Insurance Providers, Here Are 21 Corps Using Drone Tech Today, https:/www.cbinsights.com/research/report/corporations-drone-technology/\#bbc. [Last seen: 08.10.2021];

46. Euro vision: unravelling the new pan-European drone regulations, https://www.airporttechnology.com/features/new-eu-drone-rules/. [Last seen: 08.10.2021];

47. Two sides of the same coin - the right to privacy and freedom of expression, https://privacyinternational.org/blog/1111/two-sides-same-coin-right-privacy-and-freedom-expression. [Last seen: 08.10.2021];

48. Judgment by European Court of Human Rights CASE: Von Hannover v. Germany, 40660/08 [2012] (7 Feb. 2012);

49. Judgment by European Court of Human Rights CASE: Uzun v. Germany, 35623/05 [2010] ECHR, (2 Dec. 2010). 